\title{
RÉGIMEN JURÍDICO BÁSICO DE LAS MATERIAS DIRECTAMENTE VINCULADAS A LA REDUCCIÓN DEL TIEMPO DE TRABAJO
}

\author{
Aitor Bengoetxea Alkorta \\ Profesor Agregado de Derecho del Trabajo y de la Seguridad Social \\ Universidad del País Vasco/ Euskal Herriko Unibertsitatea (UPV/EHU)
}

DOI: $10.1387 /$ lan-harremanak. 16560

\section{ABSTRACT}

El Derecho del Trabajo ha conocido una evolución histórica lineal de reducción del tiempo de trabajo. Sin embargo el siglo XXI observamos cómo están tomando fuerza corrientes revisionistas que abogan por ampliar la jornada laboral, para mejorar la competitividad de los países más desarrollados con respecto a los países emergentes, donde la jornada laboral es más amplia.

Centrándonos en el derecho positivo actual, y desde el prisma de Gipuzkoa, debemos empezar por constatar que el marco jurídico que regula el tiempo de trabajo, condicionando la implementación de una politica de reducción del tiempo de trabajo en Gipuzkoa, es ciertamente complejo. En lo que respecta a la distribución competencial, nos encontramos ante una materia donde inciden competencias de la Unión Europea, del Estado, de la Comunidad Autónoma Vasca, del Territorio Histórico de Gipuzkoa, y de la autonomía colectiva (reconocida conjuntamente a representantes de empresas y personas trabajadoras).

Además, conviene dividir la materia genérica del tiempo de trabajo en cuatro elementos, a los que el derecho del trabajo actual dota de régimen juridico específico: jornada máxima; horas extraordinarias; trabajo a tiempo parcial; y reducción del tiempo de trabajo. 
Palabras clave: Reducción del tiempo de trabajo; reparto del empleo; jornada máxima; horas extraordinarias; trabajo a tiempo parcial.

Lanaren zuzenbidearen historian zehar, lanaldiaren murrizketa etengabea izan da. Baina, XXI. mendean, indartzen ari dira joera hori irauli nahi duten korronteak, lanaldia luzatzea planteatuz, garatuen dauden herrialdeen lehiakortasuna hobetzeko gorabidean dauden herrialdeekiko, azken hauetan lanaldia luzeagoa baita.

Egungo zuzenbide positibora etorrita, eta Gipuzkoaren ikuspegitik, nabarmena da lan-denboraren araubidea, lan-denbora murrizteko politika baldintzatzen duena, oso konplexua dela. Eskumenen banaketaren arabera, gai horretan Europako Batasuna, Estatua, Euskal Erkidego Autonomoa, Gipuzkoako Lurralde Historikoa, eta autonomia kolektiboaren (enpresaburuen eta langileen ordezkariei batera aitortua) eskumenak daude.

Gainera, lan-denboraren gaia lau zatitan banatzea komeni da, lan-zuzenbideak lau elementu horiek berariazko araubidez hornitu baititu: gehienezko lanaldia; aparteko orduak; denbora partzialeko lana; eta lan-denboraren murrizketa.

Gako-hitzak: Lan-denboraren murrizketa; enpleguaren banaketa; gehienezko lanaldia; aparteko orduak; denbora partzialeko lana.

Labour Law has known a regular historical evolution of reduction of working time. However, in the XXI century there are revisionist currents that support extending the working time, to improve the competitiveness of the most developed countries with regard to emerging countries, where the working time is wider.

Focusing on the current positive law, and from the perspective of Gipuzkoa, we can clearly see that the legal framework regulating working time is certainly complex, and the implementation of a policy of reducing working time in Gipuzkoa depends on it. With regard to the distribution of powers, we have a matter which affect powers of the European Union, the Spanish State, the Basque Autonomous Community, the Historical Territory of Gipuzkoa, and collective autonomy (recognized jointly to employers association and worker unions).

In addition, we must divide the generic terms of reducing working time on four elements, because labour law has given specific legal regime to each of them: maximum working hours; extraordinary hours; part-time job; and reduction of working time.

Keywords: Reduction of working time; job sharing; maximum working hours; extraordinary hours; part-time job. 


\section{Introducción}

La limitación del tiempo de trabajo es una materia que regularon las primeras normas que abordaron la cuestión social, en el siglo xIx. Se trataba de limitar las insoportables jornadas laborales del período posterior a la Revolución Industrial (siglos XVIII-XIX).

En Gran Bretaña, cuna de la Revolución Industrial, se promulgaron las primeras leyes de fábricas, factory acts. La primera fue The Factory Health and Morals Act, en 1802, que, entre otras medidas, dispuso la jornada máxima de 12 horas para los aprendices.

En el Estado español, la primera ley laboral fue la Ley Benot, en 1873, norma que prohibió el trabajo a niñas y niños menores de 10 años, y limitó a ocho horas el trabajo de los jóvenes de trece a quince ańos, y de las jóvenes de catorce a diecisiete.

Posteriormente, con la madurez del derecho del trabajo, ya en el siglo xx, se generalizó la jornada máxima de 8 horas diarias. En el Estado español, esa conquista histórica se produjo en 1919.

Actualmente, en el siglo XXI, nos encontramos con la paradoja de que, tras una evolución histórica lineal de reducción del tiempo de trabajo, están tomando fuerza corrientes revisionistas que abogan por ampliar la jornada laboral, para mejorar la competitividad de los países más desarrollados con respecto a los países emergentes, donde la jornada laboral es más amplia. Esa es la línea que se observa en los actuales estudios preparatorios de la Comisión Europea, de cara a una futura revisión del actual régimen plasmado en la Directiva 2003/88, que analizaremos infra.

Centrándonos en el derecho positivo actual, y desde el prisma de Gipuzkoa, debemos empezar por constatar que el marco jurídico que regula el tiempo de trabajo, condicionando la implementación de una política de reducción del tiempo de trabajo en Gipuzkoa, es ciertamente complejo.

Desde el punto de vista competencial, nos encontramos ante una materia donde inciden competencias de la Unión Europea, del Estado, de la Comunidad Autónoma Vasca, del Territorio Histórico de Gipuzkoa, y de la autonomía 
colectiva (reconocida conjuntamente a representantes de empresas y personas trabajadoras).

Además, conviene dividir la materia genérica del tiempo de trabajo en cuatro elementos, a los que el derecho del trabajo actual dota de régimen jurídico específico: jornada máxima; horas extraordinarias; trabajo a tiempo parcial; y reducción del tiempo de trabajo.

Dentro de esos cuatro elementos, hay cuestiones que se pueden establecer con carácter obligatorio, a modo de medida coercitiva, mientras que otras medidas podrían plantearse con carácter voluntario para las personas destinatarias.

Seguidamente se procederá al análisis separado del marco jurídico básico de los cuatro elementos arriba señalados.

\section{Jornada máxima}

Se trata de una materia de competencia estatal, en el marco de la normativa mínima europea. En esta materia no hay competencias de regulación, ni autonómicas, ni de Gipuzkoa.

En el ámbito de la Unión Europea, la Directiva 2003/88 establece una duración máxima del tiempo de trabajo semanal de 48 horas, incluidas las horas extraordinarias (art. 6). Además, se introduce el elemento flexible de la jornada semanal media de 52 horas anuales (art. 17).

Mención específica merece la posibilidad de opt-out (art. 22). Se facilita la inaplicación del mencionado límite máximo e las 48 horas semanales, si la persona trabajadora voluntariamente consiente trabajar por encima de ese umbral.

La cláusula opt-out merece una valoración netamente negativa. Podríamos decir incluso que ataca a la propia ratio essendi del derecho del trabajo. De poco sirve la abundancia de normas protectoras de trabajadoras y trabajadores, si hay una cláusula que hace pender todo ese andamiaje normativo de la voluntad de la parte débil del contrato de trabajo. También se obvia el protagonismo de los representantes colectivos de la parte trabajadora, recayendo la facultad decisoria exclusivamente en la trabajadora o trabajador individualmente considerado.

Los Estados miembros de la UE pueden mejorar la regulación de la Directiva 2003/88, reduciendo el límite europeo de las 48 horas semanales.

En la normativa estatal, la Constitución española ordena a los poderes públicos que garanticen a las personas trabajadoras el "descanso necesario, mediante la limitación de la jornada laboral» (art. 40.2 CE). Actualmente, esa limitación consiste en 40 horas semanales de promedio, en cómputo anual, de manera que 
algunas semanas puede superarse ese umbral, siempre que esa extralimitación se compense en otras semanas, para no superar el cómputo de promedio anual (art. 34 del Estatuto de los Trabajadores, en adelante, ET) ${ }^{1}$.

Esas amplias posibilidades de jornada irregular, que permiten ajustar al máximo la jornada laboral en función de la demanda, suponen otorgar máxima flexibilidad a la gestión de las personas incluidas en la plantilla de la empresa, en dirección contraria a la generación de nuevo empleo.

En cómputo diario, la legislación estatal establece el máximo de 9 horas, que puede ser modificado mediante convenio colectivo.

La legislación estatal establece con carácter indisponible el mínimo de 12 horas de descanso entre el final de una jornada laboral y el comienzo de la siguiente (art. 34 ET). Se mejora así la regla de la Directiva 2003/88, que fija un descanso mínimo diario de 11 horas (art. 3).

En lo que respecta al descanso semanal, la Directiva 2003/88 establece un mínimo de un día a la semana (art. 5), y la normativa estatal mejora esa disposición, estableciendo un día y medio, también como regla mínima, siempre mejorable mediante convenio colectivo o contrato de trabajo individual (art. 37 ET).

Por consiguiente, ese es el panorama de mínimos que dibujan la normativa europea y estatal. Acercándonos más a Gipuzkoa, hay que subrayar que los poderes públicos autonómicos (Parlamento Vasco y Gobierno Vasco), y de Gipuzkoa (Juntas Generales y Diputación), no tienen competencias directas en la regulación de la materia, y sólo podrían incidir en rebajar la jornada máxima mediante estímulos económicos, en forma de subvenciones o exenciones fiscales.

En el ámbito de la autonomía colectiva, los convenios colectivos pueden establecer una jornada máxima inferior, de cualquier número máximo de horas, en el ejercicio normal de la autonomía colectiva que tienen reconocida (art. $34 \mathrm{ET}$ ).

Así, en el territorio de Gipuzkoa, pueden establecer, con carácter vinculante, la reducción de la jornada máxima legal, convenios de distinto ámbito, partiendo de la premisa de que «los convenios colectivos tendrán el ámbito de aplicación que las partes acuerden" (art. $83 \mathrm{ET}$ ).

Por una parte, pueden hacerlo los convenios de ámbito de empresa, aplicable a las personas trabajadoras de ese determinado ámbito. También, los convenios sectoriales, aplicables a las personas trabajadoras de determinado sector productivo.

${ }^{1}$ Real Decreto Legislativo 2/2015, de 23 de octubre. 
Además, caben los convenios colectivos interprofesionales (a nivel estatal, autonómico, o de Gipuzkoa). Se trata de convenios sobre materias concretas (en este caso, jornada máxima), de los previstos en el art. 83.3 del ET. Un convenio estatal o autonómico vasco sería de aplicación obligatoria para todas las empresas y personas trabajadoras de Gipuzkoa, y debería ser aprobado por sindicatos y patronal del respectivo ámbito, estatal o autonómico. En el ámbito de Gipuzkoa, se podría establecer una jornada máxima para todos los sectores del Territorio Histórico, pero deberían acordarlo la patronal (ADEGI), y los sindicatos más representativos (ELA, LAB, UGT, CC.OO.), o, al menos, de entre los sindicatos, los que representen a la mayoría de personas empleadas en Gipuzkoa.

\section{Horas extraordinarias}

Las horas extraordinarias son aquellas que se realizan superando el umbral de la jornada máxima ordinaria (art. 35 ET).

La realización de horas extraordinarias es voluntaria para ambas partes. La cuestión puede estar prevista en convenio colectivo, donde están reflejadas las voluntades colectivas de empresas y personas trabajadoras, o, en su defecto, puede pactarse en el plano individual, entre trabajadora o trabajador y su empresa.

Más allá de su régimen jurídico, es una materia sujeta a tensiones por las tendencias contrapuestas que existen al respecto. Para favorecer la creación de empleo, se aboga por su limitación, e incluso supresión. Desde el punto de vista individual de algunas personas trabajadoras, es un supuesto apetecible por el incremento salarial que comporta.

La regulación del régimen jurídico de las horas extraordinarias es una materia de competencia estatal. En este ámbito no hay competencias autonómicas, ni de Gipuzkoa. Sólo el Estado puede establecer el régimen jurídico de las horas extraordinarias (art. 35 del ET).

En lo que respecta a su retribución, el trabajo realizado como hora extraordinaria puede ser retribuido mediante salario, o compensado en descanso de tiempo equivalente. La opción corresponde a los convenios colectivos o, en su defecto, al pacto individual entre empresa y persona trabajadora.

Hay que destacar que, en esta materia, el Gobierno estatal, mediante norma reglamentaria, dispone de amplias facultades para prohibir o limitar la realización de horas extraordinarias, favoreciendo de esa manera el reparto del tiempo de trabajo. Es claro en ese sentido el art. 35.2 del ET, cuando indica «que el Gobierno podrá suprimir o reducir el número máximo de horas extraordinarias por tiempo determinado, con carácter general o para ciertas ramas de actividad o ámbi- 
tos territoriales, para incrementar las oportunidades de colocación de los trabajadores en situación de desempleo».

Sin embargo, actualmente ni el legislador ni el ejecutivo estatal han adoptado medidas para restringir el trabajo mediante horas extraordinarias. Antes al contrario, cuando se indica que la cuantía a abonar en "ningún caso podrá ser inferior al valor de la hora ordinaria», se permite el mismo salario por horas ordinarias o extraordinarias, de manera que se está facilitando el recurso empresarial a esta fórmula, al no tener ninguna penalización económica. Por el contrario, a menudo los convenios colectivos establecen una retribución superior a la que corresponde a las horas ordinarias.

También favorece la realización de horas extraordinarias la regla del máximo de 80 horas extraordinarias al ańo que, cuando se compensan con descanso, en los cuatro meses siguientes a su realización, el contador se pone a cero (art. 35 ET).

En lo que respecta al ámbito de la autonomía colectiva, los convenios colectivos tienen capacidad para establecer un régimen propio de las horas extraordinarias, pudiendo establecer medidas que restrinjan o incluso prohíban su realización.

Es un tema difícil para los sindicatos, por la tensión entre el fomento del reparto del tiempo de trabajo, desde una perspectiva colectiva y solidaria, y la permisividad con las horas extraordinarias, desde el prisma individual, por ser atractivas desde el punto de vista económico.

En el ámbito de Gipuzkoa, pueden establecer, con carácter vinculante, un régimen específico de las horas extraordinarias, convenios de distinto ámbito. Pueden hacerlo los convenios de empresa, así como los sectoriales.

Además, pueden intervenir en la material convenios colectivos interprofesionales (a nivel estatal, autonómico, o de Gipuzkoa). Se trata de convenios sobre materias concretas (en este caso, horas extraordinarias), de los previstos en el art. 83.3 del ET. Un convenio estatal o autonómico vasco sería de aplicación obligatoria para todas las empresas y personas trabajadoras de Gipuzkoa, y debería ser aprobado por sindicatos y patronal del respectivo ámbito, estatal o autonómico. En el ámbito de Gipuzkoa, se podría establecer un régimen específico de horas extraordinarias para todos los sectores del Territorio Histórico, pero deberían acordarlo la patronal (ADEGI), y los sindicatos más representativos (ELA, LAB, UGT, CC.OO.), o, al menos, de entre los sindicatos, los que representen a la mayoría de personas empleadas en Gipuzkoa.

Los poderes públicos autonómicos (Parlamento Vasco y Gobierno Vasco), y de Gipuzkoa (Juntas Generales y Diputación), sólo podrían incidir en rebajar o suprimir las horas extraordinarias mediante estímulos económicos, en forma de subvenciones o exenciones fiscales. 


\section{Trabajo a tiempo parcial}

Actualmente, la regulación del trabajo a tiempo parcial es totalmente flexible, no hace falta causa que la justifique. Ni siquiera debe haber un determinado nivel de reducción en relación al trabajo a tiempo completo: «El contrato de trabajo se entenderá celebrado a tiempo parcial cuando se haya acordado la prestación de servicios durante un número de horas al día, a la semana, al mes o al año, inferior a la jornada de trabajo de un trabajador a tiempo completo comparable» (art. $12 \mathrm{ET})$.

En los contratos a tiempo parcial no pueden realizarse horas extraordinarias $^{2}$, pero el número de horas de trabajo, con respecto a las horas ordinarias, puede verse aumentado mediante el pacto de horas complementarias. Sólo procede cuando la jornada ordinaria sea de 10 horas semanales, como mínimo. El máximo de horas complementarias es del 30\% de las horas ordinarias, ampliable hasta el 60\% mediante convenio colectivo, y ambas modalidades se retribuyen con la misma cuantía.

Ante la disyuntiva entre contratos a tiempo parcial o a tiempo completo, el derecho del trabajo actual permanece neutro. La libertad es plena para celebrar contratos de trabajo a tiempo completo o a tiempo parcial, sin que se requiera ningún tipo de causalidad para poder pactar contratos del segundo tipo.

La variable del tipo de jornada es difícil de valorar ya que, al contrario de lo que sucede con la estabilidad laboral, que siempre favorece a la persona empleada y es la preferida por el derecho, la preferencia de la jornada a tiempo parcial frente a la jornada a tiempo completo puede convenir a la empresa (por la necesidad limitada de fuerza de trabajo), a la persona empleada (por motivos personales y/o económicos), o a ambos.

Los registros de contratos no nos ofrecen ese dato, de manera que, en cada contrato a tiempo parcial, no sabemos a ciencia cierta en presencia de cuál de las tres situaciones mencionadas estamos, tan sólo la aproximación a través de datos estadísticos.

En los últimos tiempos, y más en el actual contexto de alto desempleo, la tendencia legislativa es clara en el sentido de fomentar los contratos a tiempo parcial. Facilitan muy notablemente la flexibilidad empresarial, sin que quepa argüir, al menos en línea de principio, que perjudican a la parte trabajadora. Además, maquillan las estadísticas de desempleo, porque computan igual que los trabajos a tiempo completo.

\footnotetext{
2 Salvo el peculiar supuesto de aquellas dedicadas a reparar siniestros u otros daños extraordinarios (art. 35. 3 ET).
} 
El régimen jurídico de la jornada de trabajo a tiempo parcial es una materia de competencia estatal. En esta cuestión no hay competencias regulatorias autonómicas, ni de Gipuzkoa. Sólo el Estado puede establecer, con carácter obligatorio, el régimen jurídico del trabajo a tiempo parcial.

Los poderes públicos de la Comunidad Autónoma Vasca (Parlamento Vasco y Gobierno Vasco), así como los de Gipuzkoa (Juntas Generales y Diputación), sólo podrían incidir en el fomento del trabajo a tiempo parcial mediante estímulos económicos, en forma de subvenciones o exenciones fiscales.

En virtud de la actual regulación jurídico-positiva estatal, conviene subrayar los efectos económicos del trabajo a tiempo parcial.

En materia salarial, el salario es proporcional al tiempo trabajado. Regla mejorable por convenio colectivo.

En lo que concierne a seguridad social, históricamente se vinculaba el monto de las prestaciones a la cuantía de las cotizaciones acreditadas, lo que redundaba en una notable reducción de las cantidades percibidas por las personas con trabajo a tiempo parcial, con respecto a las personas trabajadoras a tiempo completo. Teniendo en cuenta que la mayoría de personas empleadas a tiempo parcial son mujeres, el Tribunal Constitucional apreció discriminación indirecta en esa regulación, lo que conllevó que en 2013 se modificara la misma, mejorando el régimen jurídico de la protección social del trabajo a tiempo parcial, en virtud del principio de asimilación al tiempo completo.

En lo que respecta al ámbito de la autonomía colectiva, los convenios colectivos tienen capacidad para establecer un régimen propio de trabajo a tiempo parcial, pudiendo establecer medidas que fomenten su uso. Por ejemplo, estableciendo un salario superior al que en principio corresponde, que sería proporcional con respecto al trabajo a tiempo completo.

\section{Reducción del tiempo de trabajo}

Nos encontramos ante una materia de competencia estatal. En esta cuestión no hay competencias reguladoras autonómicas, ni de Gipuzkoa. Sólo el Estado puede establecer el régimen jurídico de la reducción del tiempo de trabajo.

Se prevén distintos regímenes jurídicos para las reducciones del tiempo de trabajo, según sean instadas por voluntad de la persona empresaria (art. 47 del ET), o por voluntad de la persona trabajadora (art. 48 ET).

En el primer caso, la empresa puede obligar a reducir el tiempo de trabajo por causas económicas, técnicas, organizativas o productivas. Esa reducción tiene efectos económicos notables en el salario, ya que según la ley el salario pro- 
porcional será proporcional al tiempo trabajado. A ese salario se le suma la correspondiente prestación por desempleo parcial. El perjuicio económico descrito puede ser salvado por el convenio colectivo, que podría establecer una regulación más favorable para la parte trabajadora.

En las prestaciones de seguridad social la cuantía de la prestación depende de la cotización, que es proporcional al tiempo parcial. Por lo tanto, las prestaciones serán de cuantía inferior a la correspondiente al trabajo a tiempo completo, aunque en este caso, con respecto a la prestación por desempleo parcial, también cotiza el Servicio Público de Empleo Estatal (antiguo INEM).

Cuando la reducción de jornada es solicitada por voluntad de la persona trabajadora, nos encontramos en el contexto de las medidas de conciliación de la vida laboral y familiar.

Así, la mencionada reducción puede materializarse mediante la excedencia para cuidado de menores y dependientes. Esa situación conlleva la reducción del salario, que es proporcional a la reducción del tiempo de trabajo.

En las prestaciones de seguridad social, aunque no hay cotización efectiva por el tiempo en excedencia no trabajado, se consideran cotizados, evitándose la reducción en las prestaciones, hasta tres años de excedencia por cuidado de hijas e hijos (coincidiendo con los tres primeros años de vida), y hasta un año de excedencia por cuidado de familiares dependientes.

En lo que respecta al ámbito de la autonomía colectiva, los convenios colectivos tienen capacidad para establecer un régimen propio de reducción del tiempo de trabajo, pudiendo establecer medidas que fomenten su uso. Por ejemplo, estableciendo un salario superior al que en principio corresponde por haberse reducido la jornada, que sería proporcional con respecto al trabajo a tiempo completo.

En el ámbito de Gipuzkoa, pueden establecer, con carácter vinculante, un régimen específico que fomente la reducción del tiempo de trabajo, convenios de distinto ámbito.

Pueden hacerlo los convenios de empresa, aplicable exclusivamente a las personas trabajadoras de la correspondiente empresa. También pueden hacerlo los convenios sectoriales, aplicables a las personas trabajadoras de determinado sector productivo de Gipuzkoa.

Además, podrían establecer un régimen jurídico específico de reducción del tiempo de trabajo convenios interprofesionales (a nivel estatal, autonómico, o de Gipuzkoa). Son convenios sobre materias concretas (en este caso, reducción de jornada), de los previstos en el art. 83.3 del ET. Un convenio estatal o autonómico vasco sería de aplicación obligatoria para todas las empresas y personas trabajadoras de Gipuzkoa, y debería ser aprobado por sindicatos y patronal del 
respectivo ámbito, estatal o autonómico. En el ámbito de Gipuzkoa, se podría establecer un régimen específico de reducción de la jornada para todos los sectores del Territorio Histórico, pero deberían acordarlo la patronal (ADEGI), y los sindicatos más representativos (ELA, LAB, UGT, CC.OO.), o, al menos, de entre los sindicatos, los que representen a la mayoría de personas empleadas en Gipuzkoa.

Los poderes públicos autonómicos (Parlamento Vasco y Gobierno Vasco), y de Gipuzkoa (Juntas Generales y Diputación), sólo podrían incidir en reducir el tiempo de trabajo mediante estímulos económicos, en forma de subvenciones o exenciones fiscales.

\section{Conclusiones}

Una política firme de reducción del tiempo de trabajo como fórmula de creación de empleo necesita instrumentos jurídicos vinculantes, de la categoría hard law.

Cuando nos planteamos incidir en el régimen jurídico de la jornada máxima y de las horas extraordinarias, para lograr su reducción; o en las fórmulas para reducir la jornada de trabajo, nos encontramos con que las herramientas para poder efectuar eficazmente esas operaciones están alojadas en los poderes del Estado español.

En efecto, estamos ante materias laborales, que son competencia exclusiva del Estado (art. 149.7 CE). Como hemos visto, la UE tiene una incidencia marginal en la cuestión de la jornada máxima, ya que establece un sistema de mínimos muy flexible. De manera que la llave la tiene el Estado.

Las competencias de los poderes públicos de Gipuzkoa y de la Comunidad Autónoma Vasca son muy limitadas, circunscribiéndose en todos los casos analizados a la posibilidad de activar mecanismos de estímulo económico, por la vía de las subvenciones directas o las desgravaciones fiscales.

Bien es cierto que la autonomía colectiva tiene un gran margen de maniobra en las cuestiones analizadas, pero su incidencia práctica es muy escasa. Técnicamente, se puede incidir en la materia, de manera vinculante, en los diferentes ámbitos de los convenios colectivos. Pero no parece que la idea de reducir el tiempo de trabajo esté entre las prioridades sindicales, y mucho menos patronales. 


\section{Bibliografía}

Alfonso Mellado, Carlos Luis y García Ortega, Jesús (1994): Jornada y ordenación del tiempo de trabajo, Tirant lo Blanch.

AzNAR, Guy (1994): Trabajar menos para trabajar todos, Hoac.

CÁmara Botía, Alberto (2000): «La organización del tiempo de trabajo en el Estatuto de los Trabajadores", Revista del Ministerio de Trabajo y Asuntos Sociales, 23.

Comisión Europea (2010): Informe relativo a la aplicación por los Estados miembros de la Directiva 2003/88/CE (la Directiva sobre el tiempo de trabajo), COM (210) 801 y 802 final, de 21 de diciembre.

De la Fuente Lavín, Mikel y Otazua Garmendia, Garikoitz (1998): «Reducción del tiempo de trabajo y paro masivo: Viejas respuestas anuevos problemas», Arxius De Sociologia, 2.

De la Fuente Lavín, Mikel (2002): El régimen jurídico de las horas extraordinarias, Granada, Comares.

Enjuto Jareño, Diego (2005): «[«La modificación de la Directiva 2003/88/CE: problemática en torno a la claúsula "opt-out», al período de referencia para el cómputo de la jornada ordinaria al concepto de «tiempo de trabajo efectivo»]», IUS Labor 3.

Panizo Robles, José Antonio (2013): «La nuevas reglas de seguridad social para los trabajadores a tiempo parcial (comentario de urgencia al contenido del Real DecretoLey 11/2013, de 2 de agosto, para la protección de los trabajadores a tiempo parcial y otras medidas urgentes en el orden económico y social)", CEF-Laboral Social.

Ruiz Elúa, Vidal (1999): «Reducción del tiempo de trabajo (RTT): Una medida concreta para la creación del empleo", Lan Harremanak-Revista de RelacionesLaborales, 1.

Ruiz ElÚa,Vidal (1995): "Reduccion de tiempo de trabajo y paro", Ekonomiaz. Revista de Economía Vasca, 31-32).

Sirvent Hernández, Nancy (2016): «El régimen jurídico de la jornada complementaria en el contrato de trabajo a tiempo parcial tras las modificaciones introducidas por el Real Decreto-Ley 16/2013, de 20 de diciembre», Trabajo y derecho, 15.

Trillo, Francisco (2015): «La inaceptable propuesta de modificación de la Directiva Europea para el tiempo de trabajo», Nueva Tribuna, 8 de marzo.

\section{Apéndice: convenios colectivos de referencia}

En el presente apéndice se pueden encontrar normas contenidas en convenios colectivos colectivos de aplicación en Gipuzkoa, y relacionadas con la reducción del tiempo de trabajo. Se han agrupado diversos convenios de aplicación en cinco sectores (Maquinaria y equipo, Transporte y almacenamiento, Actividades financieras y de seguros, Administración pública y Actividades sanitarias), que son los que en otro artículo de esta obra se señalan como los más apropiados para la aplicación de políticas de reducción del tiempo de trabajo ${ }^{3}$.

\footnotetext{
3 Castrillón Sena, V./Zendoia Sainz, J.M./Zubiri Rey, J.B., «Distribución funcional de la renta y costeslaborales unitarios en Gipuzkoa (1995-2012)", Lan Harremanak: Revista de relaciones laborales, n. ${ }^{\circ} 34,2016(1)$.
} 
En general, el contenido en la materia que nos interesa es escaso, máxime teniendo en cuenta las amplísimas posibilidades de que disponen los convenios colectivos. Hay que subrayar, en positivo, que existen convenios en los que se prevén medidas de reducción de las jornadas laborales, como el correspondiente al personal laboral docente (con un apartado específico sobre reparto de empleo) o el de los trabajadores en residencias de personas mayores (en el que queda suprimida la posibilidad de realizar horas extraordinarias, salvo en supuestos de fuerza mayor).

El apéndice recoge normas contenidas en 15 convenios, encuadrables en los cinco sectores arriba mencionados, a saber:

- Maquinaria y equipo:

1. Comercio del Metal.

— Transporte y almacenamiento:

2. Transporte internacional.

3. Transporte de mercancías por carretera.

4. Transporte de viajeros por carretera.

- Actividades financieras y de seguros:

5. Banca.

6. Seguros.

—Administración Pública:

7. Laborales en la Administración de la CAV.

8. Laboral Departamento Educación (no docentes).

9. Laboral Docente Educación.

10. Instituciones locales CAV.

—Actividades sanitarias:

11. Ambulancias.

12. Farmacias.

13. Osakidetza.

14. Residencias personas mayores.

15. Clínicas. 
1. Convenio colectivo del Comercio del Metal de Gipuzkoa 2005-2008 (Boletín Oficial de Gipuzkoa, 15-1-2007)

\section{Jornada de trabajo}

La jornada fijada, en cómputo anual, será de 1.735 horas durante el año 2006, de 1.731 horas en el año 2007 y de 1.727 durante el año 2008, siendo el máximo de la jornada semanal de 40 horas.

\section{Horas extraordinarias}

Dada la situación actual de desempleo y con el fin de paliar sus efectos, no podrán efectuarse, como norma general de trabajo, horas extraordinarias, quedando exceptuadas aquellas situaciones en que por causas de fuerza mayor o por existir períodos punta de producción, ausencias imprevistas, cambios de turno o necesidades estrictas de mantenimiento, fuese necesaria su realización y no fuera posible su sustitución por contrataciones temporales o a tiempo parcial. A este respecto, en el seno de cada Empresa, la representación legal de los trabajadores y la Dirección de ésta, determinarán los distintos supuestos puedan incluirse en las causas señaladas en el apartado anterior. En cualquier caso, los Delegados de Personal y miembros del Comité de Empresa, serán informados mensualmente de las horas extraordinarias que se hayan efectuado, así como de las causas que lo motivaron. Esta información irá firmada y sellada por la Empresa. Mediante acuerdo entre la Dirección de la empresa y la representación de los trabajadores se fijará la cuantía de las horas extras y/o su compensación mediante descanso.

2. Convenio colectivo de Empresas Transitarias de 2009-2014 (Boletin Oficial de Gipuzkoa, 28-10-2013)

\section{Jornada de trabajo}

La jornada laboral máxima en cómputo anual será de 1.686 horas.

La jornada de trabajo de los sábados se realizará como máximo hasta las 12.00 horas.

En todo caso, el personal tendrá derecho a librar dos sábados por cada tres.

3. Convenio colectivo de Transportes de Mercancías por Carretera de Gipuzkoa de 2007-2009»

(Boletin Oficial de Gipuzkoa, 22-7-2008)

\section{Jornada de trabajo}

Se establece una jornada laboral anual de 1.692 horas para el año 2007.

Se establece una jornada laboral anual de 1.688 horas para el año 2008.

Se establece una jornada laboral anual de 1.684 horas para el año 2009. 
Bajo el principio de avanzar en la racionalización de la jornada laboral, se establecerá en las Empresas por el procedimiento de turnos rotativos, un sábado vacacional cada dos semanas, según lo permita la plantilla y las necesidades del servicio, que no podrá por esta causa, verse interrumpido.

Las empresas vendrán obligadas a confeccionar el calendario laboral, antes del 31-12-07, 31-12-08 y 31-12-09 poniéndolo en lugar visible en el tablón de anuncios.

Disponibilidad de horas:

A) Dentro de la jornada ordinaria de trabajo, la Dirección de la Empresa que tenga estipulado un calendario laboral, podrá disponer de hasta un máximo de 65 horas anuales durante 2007 y siguientes, que podrá utilizar tanto para atender emergencias, plazos de entrega con márgenes muy estrictos cuyo no cumplimiento pueda implicar la pérdida del pedido o cliente, etc., como, en caso contrario, en momentos de disminución de la actividad por causas del mercado, cartera de pedidos, que puedan afectar al normal desarrollo de la Empresa.

En cualquier caso, la utilización de las horas de disponibilidad a que se hace referencia en el párrafo anterior, no podrá implicar ningún incremento en la jornada anual que tenga establecida la Empresa.

El aumento o disminución de las horas como consecuencia de la utilización de las horas de disponibilidad arriba mencionadas, podrá afectar a la totalidad de la Empresa, secciones de la misma o a trabajadores individualmente.

Para que sea de obligado cumplimiento la orden dada para atender lo anteriormente citado, será suficiente $\mathrm{y}$, necesario, salvo acuerdo en cualquier otro sentido entre la Dirección de la Empresa y la representación de los trabajadores, que se cumplan los siguientes requisitos:

1. Preaviso de 72 horas a los afectados y a la representación de los trabajadores en la Empresa, con información por escrito de las razones que lo justifican.

2. ${ }^{\circ}$ Cuando la utilización de la disponibilidad horaria consista en el aumento de horas de trabajo, éste se efectuará incrementando hasta 9 horas la jornada de los días que figuren como de trabajo en los correspondientes calendarios de la Empresa.

Excepcionalmente podrá la Dirección de la Empresa ordenar el trabajo en otros días distintos, excluidos domingos, festivos, puentes y vacaciones, pero estos días no podrán exceder de 4 al año. En estos casos, la jornada no podrá ser inferior a 6,30 horas ni superior a 9 .

3. ${ }^{\circ}$ Cuando la utilización de la disponibilidad horaria consista en la disminución de horas, ésta se efectuará reduciendo en todo (hasta un máximo de 
cinco días) o en parte (como máximo de hasta dos horas diarias) la jornada de los días que por calendario corresponda trabajar.

Su compensación se efectuará aumentando hasta 9 horas la jornada de los días que por calendario, corresponda trabajar o, excepcionalmente, en otros días distintos, excluidos domingos, festivos, puentes y vacaciones, pero éstos no podrán exceder de 4 al año, sin que en ningún caso pueda verse incrementado el número de días de trabajo que corresponda trabajar anualmente a cada trabajador.

Las horas de disponibilidad no podrán ser compensadas económicamente sino que se compensarán en tiempo libre dentro del año mediante acuerdo entre las partes. De no llegarse a un acuerdo en la modificación planteada, cada una de las partes elegirá la mitad de la mismas.

B) Las Empresas que hagan uso de la facultad que se recoge en el presente artículo deberán ponerlo en conocimiento de la Comisión Mixta, sita en la calle Portuetxe bidea, n. 9 de Donostia-San Sebastián, informando de las razones que lo han motivado e indicando número de trabajadores afectados $\mathrm{y}$, número de horas globales utilizadas o a utilizar. tor

C) La disponibilidad de horas no es de aplicación a la jornada del conduc-

\section{Horas extraordinarias}

Horas estructurales: Se considerarán horas estructurales las horas extraordinarias que vengan motivadas por necesidades del servicio, períodos punta de producción, ausencias imprevistas, cambio de turnos y otras circunstancias de carácter estructural derivadas de la naturaleza de la actividad de que se trate, siempre que no puedan ser sustituidas por la utilización de las distintas modalidades de contratación previstas legalmente, procedimentalmente, se concretarán en el ámbito de la Empresa entre los representantes de los trabajadores y la dirección de la misma.

Su realización será completamente voluntaria por parte de los trabajadores, salvo las excepciones previstas en la Ley vigente.

Cada hora de trabajo se abonará con el incremento que se fije en el Convenio Colectivo o contrato individual, que en ningún caso podrá ser inferior al $75 \%$ sobre el salario que corresponda a cada hora ordinaria.

El número de horas extraordinarias no podrá ser superior a 80 al año. 


\section{Convenio colectivo de Transporte de Viajeros por Carretera de Gipuzkoa para los ańos 2006-2014 (Boletin Oficial de Gipuzkoa, 23-9-2013)}

\section{Jornada de trabajo}

1. La duración máxima de la jornada ordinaria de trabajo será de 40 horas semanales de trabajo efectivo de promedio en cómputo anual, con un máximo de 1.804 horas anuales desde el primero de enero de 2006 hasta el 31 de diciembre de 2007, y con un máximo de 1.800 horas anuales desde el primero de enero de 2008 sin perjuicio de lo dispuesto en los artículos siguientes.

2. Dicha jornada que para los conductores de servicios discrecionales será distribuida en 5 días semanales, podrá alcanzar las 12 horas de disponibilidad, de tal forma que entre la primera toma del servicio diario y el último deje del mismo, haya un máximo de 12 horas consecutivas.

3. Por otra parte, y considerando las especiales características que la realización de los servicios discrecionales lleva aparejadas, los conductores que efectúan esta clase de servicios, excluyendo los servicios de reiteración de itinerario para escolares y trabajadores, podrán superar las 12 horas de disponibilidad en virtud de las necesidades del servicio.

Tales excesos sean de disponibilidad o constituyan horas extraordinarias, tendrán la consideración de estructurales, cuando se efectúen por alguna de las necesidades reguladas en el artículo 1 de la OM de 1-3-83.

Tendrán la consideración de horas extraordinarias, aquéllas que rebasen semanalmente las 40 horas de trabajo efectivo o las 20 horas de disponibilidad.

El exceso de horas sobre la jornada semanal, podrá ser compensado con descansos, que se disfrutarán en períodos de hasta doce semanas. Si tales descansos compensatorios no se dieran, se abonarán como horas extraordinarias. Fijándose el precio en el ámbito de cada Empresa y partiendo su valor como mínimo, del precio hora normal de trabajo.

El cómputo de los tiempos de espera en los que el trabajador no esté sujeto a la vigilancia del vehículo y que no estén incluidos en la hora de disponibilidad, se efectuará por mitad cuando se trate de esperas en localidades distintas a las del principio y fin del trayecto. Estas horas no se computarán dentro de la jornada de trabajo efectivo ni se computarán a efectos de límite de horas extraordinarias, sin perjuicio de que su remuneración salarial global sea, como mínimo, de igual cuantía que la de las horas ordinarias.

4. Los conductores de servicios discrecionales contarán con una hora ininterrumpida para comer, dentro de las 12 horas de disponibilidad a que se refiere el párrafo anterior. Tal hora no será considerada como hora disponible. 
5. Toma y deje.

El comienzo de la jornada de trabajo será la que se fija para la entrada en los lugares ordinarios de trabajo o bien el comienzo del servicio en los lugares habituales señalados por cada Empresa dándose por concluida cuando se dé por finalizado el trabajo efectivo o bien las labores que deban realizarse para dejar el servicio en los mencionados lugares ordinarios de trabajo.

\section{Horas extraordinarias}

Al objeto de favorecer la creación de empleo, ambas partes acuerdan la conveniencia de reducir al mínimo indispensable las horas extraordinarias, esto es, las realizadas por encima de la jornada ordinaria de trabajo, y ello con arreglo a los siguientes criterios:

a) Horas extraordinarias habituales: supresión total y absoluta.

b) Horas extraordinarias necesarias por haberse producido imprevistos, ausencias, interrupciones del servicio, alteraciones en los turnos de personal u otras circunstancias de carácter estructural derivadas de la actividad o servicio del que se trate: mantenimiento siempre y cuando no quepa la utilización de las distintas modalidades de contratación temporal o parcial previstas legal o reglamentariamente.

En todo caso el número de horas extras no podrá exceder de 80 al año por trabajador o trabajadora.

Las horas extraordinarias que se realicen se compensarán, con carácter general, en descanso y cada una de ellas dará derecho a un descanso compensatorio de hora y media si es laborable y de 2 horas en el excepcional e inaplazable caso de que sea nocturno, en domingo o día festivo.

Dicha compensación se contabilizará en cómputo mensual, pudiendo disfrutarse la misma en el mes siguiente de acuerdo con la Dirección de Servicios u Órgano autorizado correspondiente.

\section{XXII Convenio colectivo estatal de Banca 2011-2014 (Boletín Oficial del Estado, 5-5-2012)}

\section{Jornada de trabajo}

1. La jornada máxima de trabajo para el sector, en cómputo anual, será de 1.700 horas, en las que están computados como de trabajo efectivo los 15 minutos diarios de descanso obligatorio. La mencionada jornada máxima se cumplirá de acuerdo con las jornadas y horarios de trabajo del personal que se definen en este mismo artículo y la normativa de general aplicación. 
2. Se mantiene el horario continuado actualmente establecido, que será el siguiente:

— Lunes a viernes: 8 a 15 horas, en las que están computados como de trabajo efectivo los 15 minutos diarios de descanso obligatorio.

- Sábados: 8 a 13,30 horas, en las que están computados como de trabajo efectivo los 15 minutos diarios de descanso obligatorio.

— Libranza de los sábados comprendidos entre el 1 de abril y el 30 de septiembre de cada año.

No obstante, con la finalidad de alcanzar la libranza de todos los sábados, en el ámbito de cada Empresa podrá acordarse con la Representación Legal de los Trabajadores la aplicación de las horas correspondientes a dichos sábados en otros días laborables de la misma o distinta semana, de forma que puedan mejorarse las posibilidades de conciliación de la vida personal de modo compatible con las necesidades del servicio.

En dicho sentido, se reconocen las previsiones recogidas en los Acuerdos de Empresa vigentes en esta materia a la fecha de firma de este Convenio. ción:

3. Alternativamente, se establece el horario partido que figura a continua-

— Lunes a jueves: 8 a 17 horas, con 1 hora de pausa para el almuerzo.

— Viernes: 8 a 15 horas, en las que están computados como de trabajo efectivo los 15 minutos diarios de descanso obligatorio.

- Del 23-V al 30-IX:

- Lunes a viernes: 8 a 15 horas, en las que están computados como de trabajo efectivo los 15 minutos diarios de descanso obligatorio.

- Libranza de todos los sábados del año.

El horario partido será voluntario y se ofrecerá por cada empresa a los empleados que estime conveniente. Las aceptaciones recibidas no podrán aplicarse en más del 25 por ciento de los centros de trabajo de cada Empresa, ni suponer más del 25 por ciento de los empleados de cada banco. La AEB comunicará a los Sindicatos firmantes del Convenio los centros afectados por la partición de horario que aquí se define y las relaciones nominales de los empleados afectados en cada centro, a medida que los nuevos horarios vayan siendo implantados, así como sus modificaciones.

Desde la entrada en vigor del Convenio a los empleados que realicen el horario partido definido en este punto en centros de trabajo radicados en Municipios de censo superior a 50.000 habitantes, se les abonará por cada día en que efectivamente cumplan dicho horario partido, en concepto de ayuda alimentaria, la cuantía de 9 euros. 
4. Las Empresas podrán establecer horarios, continuados o no, distintos para el personal directivo y auxiliar del mismo (incluidos los Chóferes) en el mínimo que precise, y para el personal de producción (Gestores y Visitadores), así como adecuar el horario de servicio al público y, por tanto, el del mínimo de personal indispensable para prestarlo, al que tengan otras entidades o establecimientos no bancarios de análoga función.

Subsistirá el sistema de turnos aplicable a los servicios mecanizados.

5. Los trabajadores que tuvieran jornadas especiales de duración más reducida con respecto a la normal, las mantendrán con la misma duración actual solamente si dichas jornadas fueran inferiores a siete horas, y tendrán derecho a entrar en el trabajo a la misma hora que el resto del personal, ya que la salida anticipada se considera como condición de derecho más beneficiosa.

6. Excepcionalmente, en los días laborables que en cada caso integren la semana natural en que cada localidad celebre su Fiesta Mayor anual, la jornada del personal será de cuatro horas de trabajo efectivo, y cuando en determinadas localidades los días de festejos reales no coincidan con los de la semana antes definida, podrán hacerse las variaciones necesarias para lograr esa coincidencia, siempre que las mismas supongan el mismo número de días laborables de reducción horaria que hubieran correspondido en la citada semana natural. Para estas variaciones será siempre necesario acuerdo formal previo de la Comisión Paritaria.

7. Se declara día de libranza no laborable el Sábado Santo, para las Empresas comprendidas en el ámbito de aplicación de este Convenio.

\section{Horas extraordinarias}

1. Conscientes las partes de la grave situación de paro existente y con el objetivo de favorecer la creación de empleo, convienen en reducir al mínimo indispensable las horas extraordinarias con arreglo a los siguientes criterios:

a) Horas extraordinarias habituales: reducción progresiva.

b) Horas extraordinarias que vengan exigidas por la necesidad de reparar siniestros u otros daños extraordinarios y urgentes: realización.

c) Horas extraordinarias necesarias por períodos punta de producción, ausencias imprevistas, cambios de turno u otras circunstancias de carácter estructural derivadas de la naturaleza de la actividad de que se trate: mantenimiento, siempre que no quepa la utilización de las distintas modalidades de contratación temporal o parcial previstas por la Ley.

2. El número de horas extraordinarias no podrá ser superior, en cada momento, al establecido por las disposiciones legales, salvo las trabajadas para prevenir o reparar siniestros u otros daños extraordinarios y urgentes. 
3. La prestación de trabajo en horas extraordinarias será voluntaria.

4. Las horas extraordinarias realizadas se registrarán día a día en una libreta individual o sistema similar, visada por el Jefe respectivo. Dicha libreta o documento similar estará a disposición del trabajador, o en su poder, cuando sus características lo permitan.

5. La Dirección de la Empresa informará trimestralmente y por escrito al Comité de Empresa, a los Delegados de Personal y Delegados Sindicales sobre el número de horas extraordinarias realizadas, especificando las causas y, en su caso, la distribución por secciones. Asimismo, en función de esta información y de los criterios más arriba seńalados la Empresa y los representantes legales de los trabajadores determinarán el carácter y naturaleza de las horas extraordinarias.

6. Durante la vigencia del presente Convenio, para la determinación del valor de la hora extraordinaria, se partirá de un valor tipo para la hora ordinaria, obtenido computando como dividendo el equivalente a 17,25 pagas (a estos efectos se entiende por paga la integrada por el sueldo más los aumentos por antigüedad, conceptos a) y b) del Artículo 12.º). El divisor será la cifra de 1.700 .

Para el cálculo del divisor correspondiente al personal con jornada menor de la normal, el divisor anterior se reducirá de acuerdo con la menor duración de la jornada.

Sobre el valor así establecido se aplicará un incremento del 75 por ciento.

\section{Convenio colectivo general de ámbito estatal para el Sector de Entidades de Seguros, Reaseguros y Mutuas de Accidentes de Trabajo (Boletin Oficial del Estado, 16-7-2013)}

\section{Jornada de trabajo}

La jornada máxima de trabajo en cómputo anual será de 1.700 horas de trabajo efectivo en cómputo anual.

2. Deberán respetarse las jornadas inferiores existentes en el ámbito de empresa en aquellos supuestos en que, antes de entrar en vigor el presente Convenio, existiera una jornada pactada, convenida o de obligado cumplimiento que estableciera un cómputo anual inferior al fijado en el número 1.

3. Las interrupciones que pudieran tener lugar durante la jornada diaria con ocasión del denominado período de descanso o pausa de desayuno no se consideran tiempo de trabajo efectivo, si bien se mantendrán como tiempo efectivo de trabajo en aquellas empresas en que esté expresamente establecida tal consideración. 
4. La distribución horaria de la jornada anual podrá realizarse de forma irregular a lo largo del año, respetando los períodos mínimos de descanso diario y semanal previstos legalmente.

En defecto de pacto, la empresa podrá distribuir de manera irregular a lo largo del año hasta 150 horas de la jornada de trabajo. Dicha distribución deberá respetar en todo caso, los periodos mínimos de descanso diario y semanal previstos en la Ley y el trabajador deberá conocer con un preaviso mínimo de 5 días el día y la hora de la prestación de trabajo resultante de aquella.

La forma de compensación horaria resultante de la distribución irregular llevada a cabo, se realizará procurando el acuerdo entre las partes. En defecto de acuerdo, la compensación horaria tendrá lugar dentro del plazo máximo de 4 meses siguientes a su realización, mediante tiempo equivalente de descanso, en unidades de tiempo equivalentes a las que se compensan, situándose su disfrute dentro de dicho periodo en función de las necesidades organizativas de la empresa que podrá, en su caso, concretar tal compensación en jornadas completas de trabajo.

\section{Horas extraordinarias}

Salvo que otra cosa se hubiera convenido al respecto, las horas extraordinarias se compensarán preferentemente por tiempo de descanso, en una proporción equivalente como mínimo al valor de la hora ordinaria, tratando que no se perjudique con ello el normal funcionamiento y organización del trabajo. Dicha compensación mediante descanso se realizará, salvo que otra cosa dispongan las partes, dentro de los 4 meses siguientes a la realización de las horas extraordinarias.

3. En atención a razones de política de empleo, se acuerda que en ningún caso el valor de la hora extraordinaria sea superior al valor de la hora ordinaria, cuando se opte por la retribución de la misma.

4.1. Naturaleza de las horas extraordinarias. Criterios:

a) Horas extraordinarias por fuerza mayor, exigidas por la necesidad de reparar siniestros u otros daños extraordinarios y urgentes: Realización.

b) Horas extraordinarias estructurales, necesarias por pedidos o períodos punta de producción, ausencias imprevistas, cambios de turno, incidencias no previsibles u otras circunstancias de carácter estructural derivadas de la actividad de las Empresas incluidas en el ámbito funcional del presente Convenio: Mantenimiento, siempre que no quepa la utilización de las distintas modalidades de contratación temporal o parcial previstas por la Ley. 
Trabajo nocturno. En todo caso, queda prohibida la realización de horas extraordinarias en trabajos nocturnos, salvo las previsiones contenidas al respecto en la normativa sobre jornadas especiales de trabajo.

5. La Dirección de la empresa informará mensualmente al Comité de Empresa, a los Delegados de Personal y Delegados Sindicales sobre el número de horas extraordinarias realizadas, especificando sus causas y su distribución.

Asimismo, en función de la tipología más arriba indicada y de la información recibida, la empresa y los representantes legales de los trabajadores determinarán el carácter y naturaleza de las horas extraordinarias.

6. La cotización por horas extraordinarias se realizará según su distinta naturaleza, conforme a las normas que resulten de aplicación en materia de Seguridad Social.

\section{Trabajo a tiempo parcial}

Cuando se realice jornada a tiempo parcial, las condiciones económicas y laborales derivadas del presente Convenio general se adaptarán también proporcionalmente, salvo gastos o suplidos regulados en el texto del Convenio.

\section{Convenio colectivo de Colectivos Laborales al Servicio de la Administración de la CAE, para los ańos 2010-2011 \\ (Boletín Oficial del País Vasco, 4-5-2010)}

\section{Jornada de trabajo}

La jornada de trabajo máxima anual normalizada para el personal incluido en el ámbito de aplicación de este Convenio será de 1.592 horas, y podrá desarrollarse en los dos regímenes de jornada normalizada que se establecen en el artículo 23. No obstante lo anterior, por necesidades de servicio debidamente acreditadas se podrá establecer la jornada continuada durante todo el año para determinados colectivos sin que en este supuesto se produzca efecto alguno en las retribuciones.

\section{Horas extraordinarias}

Al objeto de favorecer la creación de empleo, ambas partes acuerdan la conveniencia de reducir al mínimo indispensable las horas extraordinarias, esto es, las realizadas por encima de la jornada ordinaria de trabajo, y ello con arreglo a los siguientes criterios:

a) Horas extraordinarias habituales: supresión total y absoluta. 
b) Horas extraordinarias necesarias por haberse producido imprevistos, ausencias, interrupciones del servicio, alteraciones en los turnos de personal u otras circunstancias de carácter estructural derivadas de la actividad o servicio del que se trate: mantenimiento siempre y cuando no quepa la utilización de las distintas modalidades de contratación temporal o parcial previstas legal o reglamentariamente.

En todo caso el número de horas extras no podrá exceder de 80 al año por trabajador o trabajadora.

Las horas extraordinarias que se realicen se compensarán, con carácter general, en descanso y cada una de ellas dará derecho a un descanso compensatorio de hora y media si es laborable y de 2 horas en el excepcional e inaplazable caso de que sea nocturno, en domingo o día festivo.

Dicha compensación se contabilizará en cómputo mensual, pudiendo disfrutarse la misma en el mes siguiente de acuerdo con la Dirección de Servicios u Órgano autorizado correspondiente.

\section{Convenio colectivo del Personal Laboral del Departamento de Educación, Universidades e Investigación \\ (Boletín Oficial del País Vasco, 31-3-2009)}

\section{Jornada de trabajo}

Se establece el siguiente régimen de jornada:

Personal de Limpieza:

1.592 horas

Cocinero o Cocinera:

1.580 horas

Personal de Cocina:

1.580 horas

Bibliotecario o Bibliotecaria:

1.592 horas

Secretario/a / Administrador/a:

1.592 horas

Jefe/a de administración:

1.592 horas

Administrativo/a:

1.592 horas

Oficial Administrativo:

1.592 horas

Auxiliar Administrativo/a:

1.592 horas

Técnico de Mantenimiento:

1.592 horas

Oficial de primera:

1.592 horas

Portero-Vigilante:

1.592 horas

Almacenero o Almacenera:

1.330 horas

Personal no cualificado:

1.592 horas 
Podrá contratarse personal con jornada reducida de distinta duración a las pactadas en este Convenio, en función de las necesidades del centro, percibiendo su retribución en proporción al número de horas contratadas.

La jornada semanal se adecuará, en todo caso, al cumplimiento del calendario del centro en que presta servicios y su jornada anual.

La jornada anual del personal fijo discontinuo será de 1.354 horas, en un periodo de prestación de nueve meses y 1.480 horas en un período de prestación de diez meses.

Los contratos eventuales de apoyo en los comedores escolares podrán ser de $10,15,20,25,30,35$ y 40 horas semanales conforme a los ratios establecidos al efecto.

\section{Horas extraordinarias}

Compensación de horas en exceso. Las horas en exceso realizadas por el personal en día laborable, cuando por razones del servicio les fueran encomendadas por sus superiores para la realización de tareas de carácter extraordinario e inaplazable, darán derecho, previa la oportuna justificación, a una compensación a razón de 1 hora y 45 minutos por cada hora trabajada. La compensación será de 2 horas por cada hora trabajada cuando aquéllas se realicen en domingo o festivo o durante el período nocturno.

\section{Convenio colectivo del «Personal Laboral Docente y Educativo del Departamento de Educación, Universidades e Investigación del Gobierno Vasco» (Boletín Oficial del País Vasco, 17-6-2004)}

\section{Medidas tendentes al reparto del empleo}

\section{Artículo 53. Reducción voluntaria de jornada}

Se podrá solicitar la reducción de jornada en la mitad o en un tercio de su jornada laboral, con la reducción proporcional de todas sus retribuciones incluidos trienios.

La concesión de reducción de jornada será incompatible con cualquier otra actividad laboral remunerada, durante el horario objeto de la reducción. La solicitud será por un plazo mínimo de un año. Una vez interrumpido este permiso no cabrá nueva solicitud hasta transcurridos 3 años desde la finalización de su disfrute. Sólo podrá solicitarse después de haber transcurrido dos ańos del ingreso o reingreso en el servicio activo. 


\section{Artículo 54. Excedencia especial}

El/la trabajador/a con dos años de antigüedad en la empresa tendrá derecho a situarse en excedencia voluntaria especial con reserva del puesto de trabajo en el mismo centro donde presta sus servicios, por el período mínimo de seis meses y máximo de un año (debiendo en el caso del personal docente coincidir —en este último caso - con alguno de los siguientes periodos: agosto-enero o febrero-julio). Este derecho no podrá ser ejercitado otra vez por el/la mismo/a trabajador/a si no han transcurrido cinco años desde el final de la anterior excedencia en el caso de personal docente y dos años desde el final de la anterior excedencia en el caso de personal educativo.

\section{Artículo 55. Regulación de la actividad docente al margen de la enseñanza reglada}

El personal docente de F.P. que imparta clases en enseñanza no reglada no podrá cobrar por las mismas, reduciéndosele, en compensación, las horas de jornada lectiva en enseñanza reglada a razón de hora y media por cada hora de no reglada.

En este mismo sentido — sin perjuicio de la normativa que regula el régimen de compatibilidades-, el Departamento de Educación se compromete a estudiar las acciones tendentes a regular la participación del personal docente del sector público en las distintas actividades no regladas relacionadas con el mismo, con objeto de sustituir el sistema actual de percepciones económicas por un sistema alternativo de reducciones horarias.

\section{Artículo 56. Permiso con retribución parcial}

La Comisión Paritaria establecerá, antes de la finalización del curso escolar 2003/04, los términos en los que se extiende al personal al que es de aplicación este Convenio la fórmula de permiso con retribución parcial prevista en el artículo 73.2 del vigente Acuerdo regulador de las condiciones de trabajo del personal funcionario docente no universitario.

\section{Jornada de trabajo}

1. Para el Personal Docente, partiendo del régimen vigente de dedicación reconocido a los docentes de 1.462 horas, la práctica de la jornada semanal, su distribución en horario lectivo o no lectivo - no pudiendo aumentarse el horario lectivo y de permanencia actualmente vigentes-, así como en su caso el complementario, será regulado al comienzo de cada curso escolar.

En este sentido, dicho régimen de jornada, dedicación y permanencia, será idéntico — en cada caso - al establecido para el personal funcionario docente público no universitario. 
Quedan exceptuadas de todo lo anterior aquellas personas contratadas por tiempo inferior, quienes de conformidad con la normativa laboral, podrán mantener su actual jornada. En paralelo, siempre que las necesidades de los centros así lo requieran, se dará opción de ampliar su jornada de trabajo hasta la totalidad, a los contratados laborales a tiempo parcial.

2. Para el Personal Educativo:

a) Se establece una jornada máxima anual de 1.480 horas, cuya realización se adecuará en todo caso al cumplimiento del calendario escolar de cada centro.

b) En consideración a sus especifidades, los/as fisioterapeutas y terapeutas ocupacionales contarán con un régimen de dedicación similar al del personal docente.

c) Los/as Especialistas de Apoyo Educativo dispondrán de un total de 10 horas mensuales para tareas de coordinación y preparación de material en el centro.

d) Para el personal que tiene encomendada la vigilancia, cuidado y atención del comedor escolar de los/as alumnos/as con n.e.e. que precisen estos servicios según su ACI (Especialistas de Apoyo Educativo), cuando por necesidades de servicio y de conformidad con la organización de trabajo se simultanee el descanso para la comida con la vigilancia y ayuda a la comida de los/as alumnos/as, el tiempo destinado a la comida se considerará como laboral. En estos casos se garantizan al/a trabajador/a 45 minutos para comida propia que se computarán como una hora.

En los supuestos descritos en el párrafo anterior, la Administración, previa presentación del justificante oportuno, abonará el importe del coste del menú cuando se haga uso del servicio de comedor escolar.

e) En el supuesto de que por necesidades de servicio los/as Especialistas de Apoyo Educativo acompañaran al/a alumno/a en actividades que exigieran pernoctar fuera de su domicilio, a efectos de acumulación horaria se computarán a razón de 1,5 días con una jornada normalizada de 8 horas. En el supuesto de coincidencia con una jornada festiva el cómputo se realizará a razón de 2 días. Similar criterio se aplicará para el personal eventual o interino que realizara dichos acompańamientos.

f) Anualmente, en el plazo de un mes desde el comienzo del curso, se facilitará al/a trabajador/a el calendario y horario en que deba prestar servicios. Este calendario será el aplicable durante todo el curso escolar estando sujetas las eventuales modificaciones — siempre con carácter excepcional y debidamente informadas - a necesidades de servicio que surgieran en su transcurso; sometiéndose en última instancia a su aprobación en la Comisión Paritaria. 
Para el personal de la categoría Especialista de Apoyo Educativo, en el supuesto de prestarse servicios en más de un centro escolar —en ningún caso más de dos- y que los calendarios escolares de los mismos difirieran, se estará a los del centro en el que desarrolla la mayor parte de su jornada diaria

\section{UDALHITZ. Protocolo marco de Relaciones Laborales para las Instituciones Locales de Euskadi (9-3-2006)}

\section{Jornada de trabajo}

1. La jornada laboral habitual del personal funcionario de la Institución será la que determina la legislación aplicable.

2. Con los objetivos de promover la conciliación de la vida laboral y de incrementar la adecuación organizativa de los servicios a las demandas ciudadanas, se establece para la jornada laboral habitual una flexibilidad horaria anual con lo que la jornada anual de presencia efectiva será como máximo de 1.592 horas.

\section{Horas extraordinarias}

1. En la búsqueda de unas condiciones de empleo de calidad en el sector público, las Organizaciones Sindicales y la Institución coinciden en la necesidad de organizar la prestación de los servicios municipales de tal modo que se reduzcan al máximo las horas realizadas fuera de la jornada habitual.

2. En este sentido se suprimen totalmente las horas realizadas fuera de la jornada normal con carácter habitual.

3. Se reducirán al mínimo imprescindible las horas que se deban realizar fuera de la jornada habitual excepto aquellas destinadas a prevenir o reparar siniestros u otros daños que ocasionen perjuicios graves a la comunidad.

4. Con carácter preceptivo y con anterioridad a su realización, excepto en aquellos casos de extraordinaria urgencia o de fuerza mayor, el Jefe de Departamento elaborará un informe propuesta en el que deberá motivar la necesidad de la realización, la previsión de los servicios a realizar y el tiempo a emplear.

5. Si en la plantilla existieran más trabajadores de los necesarios y con la cualificación adecuada para realizar las tareas extraordinarias, tendrán prioridad para realizarlas los que fueran voluntarios.

6. Trimestralmente la Institución hará público un informe detallando el número de horas extraordinarias realizadas al amparo de los apartados 3 y 4 de este artículo y las medidas adoptadas para reducirlas en el futuro.

7. Los informes elaborados por la Institución serán remitidos a la Comisión Paritaria de Seguimiento y a la Comisión Paritaria y de Mediación, Interpreta- 
ción y Conciliación establecida en el marco del Protocolo de Relaciones Laborales para las Instituciones Locales de Euskadi.

8. La comisión Paritaria de Seguimiento debatirá y negociará la información suministrada y atenderá las indicaciones y recomendaciones que, en su caso, emita la Comisión Paritaria y de Mediación, Interpretación y Conciliación.

9. Las horas realizadas fuera de la jornada habitual se compensarán en tiempo de descanso, salvo que por necesidades del servicio no fuese posible; en este último supuesto se aplicará lo previsto en el título segundo de este Acuerdo.

10. Para la compensación en tiempo de libranza se seguirán los siguientes criterios:

11. Cada hora realizada fuera de la jornada laboral establecida dará derecho con carácter general, a un descanso compensatorio de hora y tres cuartos, si es laborable.

12. Y de dos horas en caso de que sea festiva o nocturna.

13. Las fechas para hacer efectivos los descansos compensatorios a los que el empleado público tenga derecho como consecuencia de la realización de dichas horas, serán elegidas por éste, de acuerdo con su jefe inmediato, dentro del trimestre natural en el que se realicen, pudiendo acumularse a fiestas o domingo, e inclusive a las vacaciones, cuando le correspondiera disfrutarlas en el trimestre.

14. Los descansos compensatorios establecidos en este artículo serán considerados, a todos los efectos, como tiempo de trabajo efectivo.

15. En todo caso, el número de horas que cada empleado puede realizar fuera de la jornada habitual no superará el límite de 60 horas anuales si realiza la jornada normal, o la parte proporcional que le corresponda si realiza una jornada inferior.

\section{Convenio colectivo de Transporte de Enfermos y Accidentados en Ambulancias de Gipuzkoa 2004-2007 \\ (Boletín Oficial de Gipuzkoa, 2-6-2005)}

\section{Jornada de trabajo}

La duración máxima de la jornada ordinaria de trabajo para el personal de estructura o de no movimiento será de 1826 horas en el 2004, 1.816 horas en el 2005, 1.806 horas en el 2006 y 1.796 horas en el 2007.

La duración máxima de la jornada ordinaria de trabajo para el personal operativo o de movimiento será de 1.826 horas en cómputo anual más las horas de presencia reflejadas en el art. 12 en el 2004, 2005 y 2006; y 1.818 en el 2007. 
La jornada máxima diaria será de ocho horas. Pudiendo la empresa establecer jornadas de hasta doce horas, hasta la desaparición definitiva de la horas de presencia establecidas en el artículo 12.

El descanso mínimo obligatorio entre jornada y jornada será de 12 horas y de la misma manera, el régimen de descanso semanal, deberá garantizar habitualmente un descanso de cuarenta y cinco horas consecutivas a la semana.

Las empresas están facultadas para organizar el trabajo de acuerdo a las necesidades del servicio, pudiendo establecer los correspondientes turnos entre el personal, para asegurar la atención preventiva y real desde las cero a las veinticuatro horas durante los trescientos sesenta y cinco días del año, previa consulta a la representación legal de los trabajadores.

Estos turnos serán rotativos o fijos.

\section{Horas extraordinarias}

No se podrán realizar horas extraordinarias con carácter habitual. Las horas de trabajo que rebasen la jornada convenida en su distribución cuatrisemanal tendrán la naturaleza de extraordinarias.

Las partes firmantes de este Convenio acuerdan reducir y evitar la realización de horas extraordinarias habituales, siendo únicamente justificada su realización por razones exclusivas de tipo estructural.

Las horas extraordinarias serán compensadas con tiempo de descanso a razón de 1,75 horas de descanso por hora extra trabajada, a disfrutar en el mes siguiente, y si no fuera posible por necesidades justificadas del servicio, se llegará a un acuerdo para su disfrute en los tres meses siguientes.

No tendrá la consideración de hora extraordinaria la ampliación de la jornada durante el tiempo estrictamente necesario, de aquellos trabajadores cuya presencia en el puesto de trabajo pone en marcha o finaliza el trabajo de los demás (solapes), siempre que esa ampliación de jornada no rebase los 15 minutos ya que en ese caso pasarían a tener la consideración de extraordinarias. El tiempo de trabajo prolongado por esta causa no se tendrá en cuenta a efectos de la duración máxima de la jornada laboral ordinaria. Las horas de solape serán compensadas con tiempo de descanso a razón del mismo tiempo de descanso por tiempo de jornada prolongada, a disfrutar en el mes siguiente, y si no fuera posible por necesidades justificadas del servicio, se llegará a un acuerdo para su disfrute en los tres meses siguientes. 


\section{Convenio colectivo de Oficinas de Farmacia (Boletin Oficial de Gipuzkoa, 9-8-2000)}

\section{Jornada de trabajo}

A jornada laboral para los años 2000, 2001 y 2002 será, respectivamente, de $1.782,1.778$ y 1.772 horas anuales de trabajo efectivo, siendo competencia exclusiva del titular de la Oficina de Farmacia la de establecer, dentro del primer mes de cada ańo los cuadros horarios de la jornada laboral ordinaria de lunes a sábado.

La jornada semanal tipo será de 40 horas, sin perjuicio de que, en algunas localidades, puedan realizarse otras jornadas semanales, siempre respetando el máximo de horas anuales.

La diferencia que pudiera producirse entre la jornada semanal y el cómputo anual se disfrutará de manera continuada, y de mutuo acuerdo entre el trabajador y el titular de la Oficina de Farmacia. Estos períodos de disfrute tendrán la consideración de vacaciones reglamentarias, para los farmacéuticos adjuntos y auxiliares, a los que se refiere el capítulo II del Decreto 129/97 de 3 de junio, sobre Dotación de medios humanos de las Oficinas de Farmacia.

\section{Horas extraordinarias}

1. Dada la obligación legal de prestar servicios de atención farmacéutica en régimen de urgencia y turnos obligatorios por parte de las Oficinas de Farmacia, el farmacéutico estará facultado, durante dicho servicio, para organizar la jornada y horario de trabajo del empleado, con permanencia efectiva en la Oficina de Farmacia, continuada o intermitentemente.

En estos supuestos el trabajador estará obligado a realizar horas extraordinarias con los límites establecidos en el Estatuto de los Trabajadores.

2. ${ }^{\circ}$ Las horas extraordinarias trabajadas durante el servicio de atención farmacéutica en régimen de urgencia y turnos obligatorios tendrán la consideración de estructurales y podrán ser abonadas, con los recargos correspondientes, o compensadas en tiempos equivalentes de descanso retribuido.

Si las horas extraordinarias son trabajadas en día festivo, su compensación en tiempo de descanso, si éste se concede en día laborable, será del 150\% (es decir una hora y media de descanso en día laborable por cada hora extraordinaria de trabajo en día festivo.)

El titular de la Oficina de Farmacia tendrá derecho a optar entre el abono de las horas extraordinarias, o su compensación en tiempo de descanso.

Los días o períodos de descanso se fijarán por acuerdo entre el empleado y el titular de la Oficina de Farmacia. 


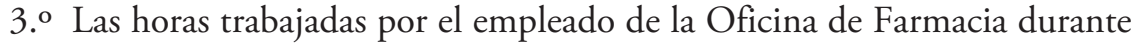
el servicio de atención farmacéutica en régimen de urgencia y turnos obligatorios prestados en día festivo, aún cuando no tengan el carácter de horas extraordinarias, serán compensadas en tiempo de descanso en la misma forma que la establecida en el apartado anterior para la compensación en tiempo de descanso de las horas extraordinarias.

4. ${ }^{\circ}$ El módulo para el cálculo de la hora extraordinaria consistirá en el cociente que resulte de dividir el salario anual entre 1.782 horas en el año 2000, entre 1.778 en el 2001 y entre 1.772 en el 2002.

Las horas extraordinarias se abonarán con los siguientes recargos:

—Diurnas: 75\% hora normal.

- Festivas: 140\% hora normal.

- Nocturnas: $100 \%$ hora normal.

Se entiende por horas diurnas las comprendidas entre las 9 de la mañana y las 10 de la noche, y horas nocturnas las de las 10 de la noche a las 9 de la mañana del día siguiente.

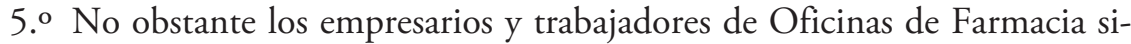
tuados en zonas rurales o de características especiales, podrán pactar en cada centro de trabajo otras formas de retribución del trabajo prestado, por causa de servicio de atención farmacéutica en régimen de urgencia y turnos obligatorios.

6. Se entiende por servicio de urgencia, el que presta el empleado con permanencia en la Oficina de Farmacia desde las 22 horas hasta las 9 de la mañana del día siguiente. La retribución de dichas horas podrá ser acordada por las dos partes y de común acuerdo en cada centro de trabajo. Se establece como norma orientativa a este efecto de remuneración del servicio nocturno de urgencia la cantidad de 12.460 ptas. para el auxiliar y 14.610 ptas. para el facultativo. Este importe se incrementará cada año en función del IPC.

13. Acuerdo regulador de las condiciones de trabajo del personal de

Osakidetza-Servicio Vasco de Salud, para los años 2007, 2008 y 2009

(Boletín Oficial del País Vasco, 31-12-2007)

\section{Jornada de trabajo}

1. Conforme a la jornada anual aprobada mediante Acuerdo de la Mesa General de negociación de la Administración de la Comunidad Autónoma de Euskadi, en el ámbito de Osakidetza para todos los tipos de jornada, excepto la nocturna, las horas de trabajo efectivo anuales a realizar en concepto de jornada ordinaria serán mil quinientas noventa y dos. 
Para los turnos nocturnos, en régimen permanente, las horas efectivas de trabajo anuales serán de mil cuatrocientas cuarenta y siete.

Quienes roten en turnos diurnos y nocturnos ajustarán su dedicación máxima a la que resulte como promedio de la aplicación proporcional de ambos horarios que, siempre, y aplicando a la hora nocturna un factor multiplicador del 1,10 , dará un resultado final igual a la jornada establecida para los turnos diurnos.

No obstante la regla general del párrafo anterior, al personal mayor de 55 años que preste sus servicios en régimen de turnos rotatorios se le aplicará a la hora nocturna el factor multiplicador que se señala a continuación, en función de la edad:

- Mayores de 55 años: 1,15.

- Mayores de 60 años: 1,20.

Igualmente, el personal mayor de 55 años podrá acogerse, con carácter voluntario, a la medida de exención de la realización de trabajo nocturno. Esta medida estará en todo caso sujeta a negociación con la Dirección-Gerencia de la Organización de servicios correspondiente, pudiendo conllevar, si así fuera necesario para su atención, un cambio de Unidad del/la solicitante.

El personal en régimen de trabajo por turnos diurnos y nocturnos ajustará su dedicación máxima a la que resulte como promedio de la aplicación proporcional de ambos horarios que, siempre, y aplicando a la hora nocturna el citado factor corrector del 1,10, o del que corresponda por razón de su edad, dará un resultado final anual igual a la jornada anual de mil quinientas noventa y dos horas establecida para los turnos diurnos.

2. Para el año 2007 se mantiene la jornada anual de 1.433 horas de trabajo efectivo para aquel personal de Instituciones Abiertas que efectuó esta jornada en el pasado año 2006.

No obstante este personal podrá solicitar la ampliación de su jornada a la establecida en el presente Acuerdo con carácter normalizado, cuya autorización corresponderá a la Dirección de la Organización de servicios correspondiente dentro de las consignaciones presupuestarias existentes en el centro. En caso de informe negativo, éste deberá ser motivado.

3. Con carácter general, salvo para el personal en sistema de turnos rotatorios y a excepción de lo que proceda en el ámbito de Atención Primaria acerca de la prestación de servicios los sábados, la jornada normalizada diaria será de 7 horas.

4. El personal prestará servicios, con carácter general, salvo quienes realicen turnos rotatorios, un máximo de seis sábados al año. En aquellos casos en que 
algún personal venga realizando un número inferior de sábados, se mantendrá dicha situación siempre que se cumpla la jornada anual establecida.

5. Siempre que la duración de una jornada exceda de seis horas continuadas existirá un período de descanso durante la misma de duración equivalente a quince minutos. Su disfrute se deberá realizar necesariamente dentro del correspondiente turno de trabajo, computándose en este caso como tiempo de trabajo efectivamente realizado.

Conforme lo anterior, en ningún caso se podrá acumular períodos de descanso no disfrutados para su disfrute en otro u otros días o períodos posteriores.

En todo caso, el momento concreto del disfrute del descanso quedará supeditado al mantenimiento de la atención de los servicios.

Asimismo, en ningún caso su disfrute efectivo supondrá un retraso en la hora de entrada al puesto de trabajo o un adelanto en la hora de salida del turno correspondiente.

6. La determinación de los turnos rotatorios en los que deba implantarse el solape, entendido como tiempo efectivo de trabajo consistente en la prolongación en diez minutos de la jornada diaria y destinados a la transmisión de los oportunos "partes» de cambio de turno, así como la determinación del personal que deba realizarlo, deberá ser objeto de negociación en el ámbito de cada Organización de servicios entre la Dirección de la misma y la representación del personal, en atención de la necesidad de que el mismo se deba realizar efectiva y justificadamente.

En situación de Incapacidad Temporal se computará el tiempo de solape al personal que lo tuviera reconocido.

7. Se establecen como principios generales para la practicidad de la jornada el establecimiento de un límite máximo de 70 horas nocturnas en cómputo de ocho semanas, excepto para el personal que presta sus servicios en turno fijo de noche, así como el derecho a la libranza de día y medio semanal ininterrumpido (72 días al año) y la libranza de un fin de semana de cada tres.

La aplicación de estos principios generales está supeditada al número real de efectivos que componen las unidades y a la demanda asistencial de las mismas.

8. A efectos de la practicidad de la jornada en el ámbito de la Atención Primaria, y sin perjuicio del cumplimiento de los sábados que con carácter general se fija en el apartado $4 .^{\circ}$ de este artículo, dicha jornada tendrá una duración general de siete horas, de lunes a viernes. 
Para ajustar las carteleras al cumplimiento de la jornada anual, podrán disponerse como fechas alternativas los días 24 y/o 31 de diciembre y/o los dos días festivos de carácter local.

La disposición de dichos ajustes se realizará en cada Organización de servicios, debiendo garantizarse siempre la cobertura y atención de las necesidades asistenciales.

9. La jornada ordinaria de trabajo del personal residente en formación será de 1.592 horas anuales de trabajo efectivo en régimen de dedicación a tiempo completo.

El personal residente que efectúe régimen de guardias tendrá una jornada normalizada de siete horas, de lunes a viernes, siempre que ello no imposibilite completar el correspondiente programa formativo.

\section{Horas extraordinarias}

\section{Artículo 28. Jornada Complementaria (Servicio de Atención Continuada)}

1. Cuando se trate de la prestación de servicios de atención continuada y con el fin de garantizar la adecuada atención permanente a los usuarios y usuarias de las Organizaciones sanitarias de Osakidetza, el personal de determinadas categorías o unidades desarrollará una jornada complementaria en la forma que se establezca a través de la programación funcional de la correspondiente organización de servicios.

2. El número máximo de guardias mensuales que con carácter general se deberán realizar será de tres (3) en el caso de un/una facultativo especialista, con las excepciones derivadas de las necesarias adaptaciones, adecuaciones y oportuna racionalización de los efectivos que componen cada una de las Unidades y de la demanda asistencial de las mismas. De forma voluntaria podrá superarse dicho límite cuando así se lo oferte la Dirección del Hospital y acepte el/la facultativo, siempre que se cumpla la normativa vigente.

El personal residente en formación estará obligado a realizar las horas de jornada complementaria que el programa formativo establezca para el curso correspondiente. En este caso, este personal no podrá realizar más de siete guardias al mes, todo ello dentro el programa formativo establecido para el curso correspondiente.

3. Se establece un módulo de prestación de servicios de atención continuada para sábados, domingos y festivos, con una duración de 24 horas ininterrumpidas, sin menoscabo de los refuerzos que sean necesarios para el pase de visita y el alta de los pacientes, con lo que la jornada ordinaria para el personal facultativo especialista en régimen de guardias queda fijado en siete horas, de lunes a viernes. 
Asimismo, en sábados, domingos y festivos, el personal residente en formación prestará servicios de atención continuada conforme a un módulo de 24 horas ininterrumpidas.

4. La jornada complementaria no tendrá en ningún caso la condición ni el tratamiento establecido para las horas extraordinarias. En consecuencia, no estará afectada por las limitaciones que respecto a la realización de horas extraordinarias establecen o puedan establecer otras normas y disposiciones, y su compensación o retribución específica son las que expresamente se fijan en el anexo correspondiente del presente Acuerdo.

5. Las guardias de presencia física realizadas por el personal facultativo, se compensarán por módulo de horas de prestación de servicios, conforme a los importes establecidos en el Anexo III, 2. Las fracciones de módulos se adecuarán en todo caso proporcionalmente.

A partir de la entrada en vigor del presente Acuerdo, la retribución de las guardias incluirá la cantidad íntegra correspondiente, que se retribuirá por tanto en el mes en que se efectúen, incluyendo la parte proporcional que hasta el momento correspondía y se incluía en las pagas extraordinarias. Conforme a lo anterior, a partir de la fecha de entrada en vigor del presenta Acuerdo no se realizará asignación alguna por las guardias en pagas extraordinarias. Se mantiene el actual prorrateo de vacaciones y la retribución de las guardias en la situación de Incapacidad Temporal.

La previsión anterior no supondrá modificación alguna en el régimen de retribución de guardias de aplicación al personal residente.

Las guardias que sobrepasen la tercera mensual se retribuirán con un incremento adicional de $10 \%$ sobre los valores establecido en el Anexo III para las guardias de presencia física o localizada, tanto en el caso de que se trate de guardia laborable como festiva.

6. Los servicios de localización se compensarán con un 50\% del importe fijado para las guardias de presencia física, con obligación de acudir al centro cuando se fuera requerido.

7. Las guardias médicas localizadas que requieran la presencia del/la facultativo en el Hospital en dos o más ocasiones, así como aquellas otras que impliquen una permanencia de cuatro o más horas en el mismo tendrán, a efectos retributivos, la consideración de guardias de presencia física.

8. Se reconoce la realización de los módulos de guardia para aquellos otros colectivos que los vienen realizando en aquellas Organizaciones en que están así establecidas por considerarse necesarias, en tanto se mantenga la organización del servicio en este sentido. Todo ello sin perjuicio de su actualización en el 
mismo porcentaje que con carácter general se establezca para los restantes conceptos retributivos de guardias.

9. Guardias del personal facultativo residente en formación.

Con efectos del día 01-01-2008 el personal facultativo residente en formación percibirá la retribución correspondiente a atención continuada / guardias en función de los siguientes porcentajes respecto del valor hora de guardia percibido por los médicos de plantilla de Osakidetza, tanto laborable como festiva:

- Facultativo R1 55\%.

- Facultativo R2 60\%.

- Facultativo R3 70\%.

- Facultativo R4 80\%.

- Facultativo R5 80\%.

Estos mismos porcentajes resultarán de aplicación en los años sucesivos.

No obstante, y siempre que la cantidad resultante fuera superior a la más arriba indicada, la retribución del valor hora de guardia de presencia física del personal facultativo residente en formación se atendrá, como valor mínimo garantizado para el año 2008, a las siguientes cuantías:

- R1: 11,50 euros;

- R2: 13,50 euros;

- R3: 15,50 euros;

- R4: 17,50 euros;

- R5: 17,50 euros.

10. Las guardias tanto de presencia física como localizadas, realizadas durante de los días 24, 25 y 31 de diciembre, así como el día 1 de enero, se retribuirán por el doble de su valor.

La previsión anterior resulta igualmente de aplicación a las guardias realizadas en dichos días por el personal residente en formación.

11. Los/as Directores Gerentes de los Hospitales podrán analizar, y en su caso pactar, con las Unidades o Servicios la conversión de actuales guardias de presencia física en guardias localizadas. La diferencia económica resultante se compensará mediante la realización proporcional de los módulos de atención continuada, cuya realización será en todo caso voluntaria.

12. Se acuerda constituir una Comisión Técnica de guardias, integrada por los firmantes del Acuerdo que analizará el actual sistema de Atención Continuada existente en cada uno de los hospitales de Osakidetza, con el fin de explorar y proponer mejoras o alternativas al modelo actual. 
Dicha Comisión estará compuesta por representantes de Osakidetza y de las centrales sindicales firmantes del Acuerdo.

\section{Artículo 29. Duración máxima conjunta de los tiempos de trabajo}

La duración máxima conjunta de los tiempos de trabajo correspondientes a la jornada ordinaria y a la jornada complementaria será de cuarenta y ocho horas semanales de trabajo efectivo de promedio en cómputo semestral.

En el caso del personal residente en formación, la duración máxima de la jornada, sumando jornada ordinaria y jornada complementaria, será la que se establece conforme a los siguientes periodos de progresiva aplicación:

a) Jornada máxima de 58 horas semanales de promedio en cómputo anual hasta el 31 de julio de 2007.

b) Jornada máxima de 56 horas semanales de promedio en cómputo anual entre el 1 de agosto de 2007 y el 31 de julio de 2008 .

c) A partir del 1 de agosto de 2008, la jornada máxima será de 48 horas semanales en cómputo anual.

La jornada laboral del personal residente en formación asegurará el cumplimiento de los programas formativos. Dentro de las posibilidades organizativas y funcionales de cada centro, se procurará disponer la jornada de los residentes de forma que la ordenación del tiempo de trabajo no perjudique la formación.

No serán tomados en consideración para la duración máxima conjunta de los tiempos de trabajo correspondientes a la jornada ordinaria y a la jornada complementaria, los períodos de localización, salvo que el personal sea requerido para la prestación de un trabajo o servicio efectivo, caso en que se computará como jornada tanto la duración del trabajo desarrollado como los tiempos de desplazamiento, computándose este tiempo de desplazamiento por un máximo de media hora.

En ningún caso se computarán a estos efectos las jornadas ordinarias no realizadas efectivamente, en cuanto tiempo que el personal no permanece en su Organización de servicios a disposición del centro y en el ejercicio efectivo de sus actividades y funciones.

El período de vacación anual retribuida y los períodos de baja por enfermedad serán neutros para el cálculo del promedio indicado. 
14. Convenio colectivo de Residencias de Personas Mayores de Gipuzkoa de 2005-08

(Boletin Oficial de Gipuzkoa, 3-2-2006)

\section{Jornada de trabajo}

La jornada laboral del personal tenderá a las 35 horas semanales de trabajo efectivo de promedio en cómputo anual, es decir, de 1.592 horas anuales. Para lograr este fin se establece para cada centro de trabajo la siguiente fórmula de reducción de jornada por año hasta lograr el objetivo fijado:

(Jornada efectiva anual de cada centro de trabajo en el año 2005) menos (1.592 horas) dividido por tres. El resultado nos dará el número total de horas a reducir cada uno de los ańos 2006, 2007 y 2008.

No se tendrá en cuenta a efectos de la duración de la jornada ordinaria o normal el exceso de horas trabajadas para prevenir o reparar siniestros y otros daños extraordinarios y urgentes.

En los casos de jornadas parciales, la reducción de jornada supondrá (salvo petición en contra de la persona afectada) el aumento del porcentaje de su jornada anual.

Cuando la jornada sea continuada se establecerá un descanso de 20 minutos que no serán considerados como tiempo de trabajo efectivo. En cualquier caso se mantendrán, de acuerdo entre la empresa y la representación de los trabajadores los tiempos de descanso distintos a los 20 minutos (en más o en menos) sin que en ningún caso sean considerados como tiempo de trabajo efectivo.

\section{Horas extraordinarias}

Queda suprimida la posibilidad de realizar horas extraordinarias, salvo en los supuestos excepcionales de fuerza mayor.

\section{Convenio colectivo de «Hospitalización, Clínicas Médico-Quirúrgicas} y de Diagnóstico»

(Boletín Oficial del País Vasco, 17-1-2000)

\section{Jornada de trabajo} bajo.

La jornada laboral para 1999 será de 1.768 horas anuales efectivas de tra-

Para el año 2000 la jornada laboral será de 1.754 horas efectivas de trabajo. 


\section{Horas extraordinarias}

Como norma general, no se trabajarán horas extras. En cualquier caso, no podrán exceder de las 80 al ańo. Las horas extraordinarias trabajadas en días laborables, domingos o festivos, se pagarán con un recargo del $75 \%$ sobre el salario hora ordinario. 